\title{
Shiga-Like Toxin and Haemolytic-Uraemia Syndrome
}

\section{E.N.}

Dr. E.N. Wardle, 20 Oxford Road, Littlemore, Oxford 0X4 4PE (UK)

Dear Sirs,

References

I was pleased to see the article of Bertani et al. [1] confirming the studies of Jack Fong who showed how endotoxin infusion reproduces the features of haemo-lytic-uraemia syndrome. Only I am left to wonder how many 'possibles' are required to make a concept probable. I also have done this infusion.

Of greater concern to me now is to rationalise the relative roles of Shiga-like toxin from enterotoxigenic Escherichia coli (ETEC) and that of lipid-A toxin of endotoxins. In spite of many suggestions [2], it is not conceivable that the cytotoxin can pass from the gastrointestinal mucosa into the systemic circulation. The defences of the liver and the fact that this is a powerful toxin that binds to globoside Gb3 mean that this notion is inadmissible.

Surely the situation is that the cytotoxin of ETEC causes mucosal erosions (and thus for instance bloody diarrhoea) and those erosions then allow the entry of endotoxins into the circulation. All the features of endo-thelial damage, including coincidental granulocyte activation, can be explained by the action of lipid-A.

Bertani T, Abbate M, Zoja C, Corna D, Remuzzi G: Sequence of glomerular changes in experimental endotoxemia: A possible model of hemolytic uremic syndrome. Nephron 1989; 53: 330-337.

Clearly TG, Lopez EL: The Shiga like toxin producing Escherichia coli and haemolytic uraemia syndrome. Pediatr Infect Dis 1989:8:720-724. 